Article

\title{
Design and Experimental Characterization of an Actuation System for Flow Control of an Internally Blown Coanda Flap
}

\author{
Peter Wierach ${ }^{1}$, Jan Petersen ${ }^{1}$ and Michael Sinapius ${ }^{1,2, *(\mathbb{D})}$ \\ 1 Institute of Composite Structures and Adaptive Systems, German Aerospace Center (DLR e.V.), \\ Lilienthalplatz 7, 38108 Braunschweig, Germany; Peter.Wierach@dlr.de (P.W.); jan.petersen@dlr.de (J.P.) \\ 2 Institute of Adaptronics and Function Integration, Technische Universität Braunschweig, Langer Kamp 6, \\ 38106 Braunschweig, Germany \\ * Correspondence: m.sinapius@tu-bs.de; Tel.: +47-531-391-2640
}

Received: 24 December 2019; Accepted: 12 March 2020; Published: 17 March 2020

\begin{abstract}
The focus of the work is on the evaluation, development and integration of a robust actuator system for three-dimensional flow control of a blown Coanda flap to improve the high lift system of commercial aircraft. As part of the research work presented, the system is integrated into a wind tunnel model in order to influence the flow across the entire width of the model. The system developed is based on individual bending transducers that can vary the height of the blowing slot dynamically. The system is divided into 33 segments and is therefore able to implement static and dynamic actuation along the wing-span (3D-actuation). All segments can be controlled independently and thus offer great optimization potential for an effective flow control. Different configurations were developed and evaluated against each other with respect to the demanding requirements (small installation space, frequency range from $5 \mathrm{~Hz}$ to $300 \mathrm{~Hz}, 1$ bar pressure, $0.4 \mathrm{~mm}$ deflection, $1 \mathrm{~m}$ span). The design of the blown flap has been specified in an iterative design process. In the final configuration, all mechanical components are reduced to the bare minimum for weight reduction reasons, in order to meet the dynamic requirements of the wind tunnel model. To characterize the lip segments, a test device has been designed that can be pressurized to generate aerodynamic loads on the lip segments. Finally, 33 lip segments were integrated into a wind tunnel model and tested intensively as part of a measurement campaign. The first aerodynamic results show an increase in lift of up to $\Delta \mathrm{C}_{\mathrm{a}}=0.57$. These aerodynamic gains are achieved at amplitudes that do not require the lip segments to completely close or open the blowing slot, which shows the advantage of the current lip design that enables activation with independently controlled stationary and unsteady components.
\end{abstract}

Keywords: active flow control; piezoelectric actuators; compliant mechanism; Coanda flap

\section{Introduction}

As part of the Collaborative Research Center 880 "Fundamentals of High Lift for Future Commercial Aircraft", the Technical University of Braunschweig and the German Aerospace Center (DLR) developed an adaptive wing profile for novel high-lift devices. The increase in future air traffic will lead to additional flights from smaller airports near urban areas. Therefore, measures must be taken to re-duce the noise level during take-off and landing phases. The efficiency of short take-off and landing (STOL) aircraft depends particularly on the achievable lift co-efficient, induced by supplementary high-lift devices. A first step to optimize the performance of commercial aircraft could be the structurally compliant integration of sensors and actuators for active flow control into the wing profile, to save weight and to reduce drag. The objective is the development of an adaptive wing, which includes 
all relevant systems for active flow control to allow the implementation of novel high-lift devices, which adapt to each flight phase. This work employs the internal blowing over carefully designed flap surfaces to achieve control authority for flow turning, hence making use of the Coanda effect [1]. One part of this system is a very compact actuated lip of a blowing slot ahead of a Coanda flap. To avoid flow separation on the Coanda flap, a closed loop-controlled system is developed in order to dynamically adjust the Coanda jet to the current state of flight. The flow condition is measured using micro engineered pressure and hot film sensors, which are integrated into the wing profile. Using an additional pressurized mass flow $\dot{m}$, the velocity of the Coanda jet is controlled by an adaptive lip that varies the height $h$ of the blowing slot (Figure 1).

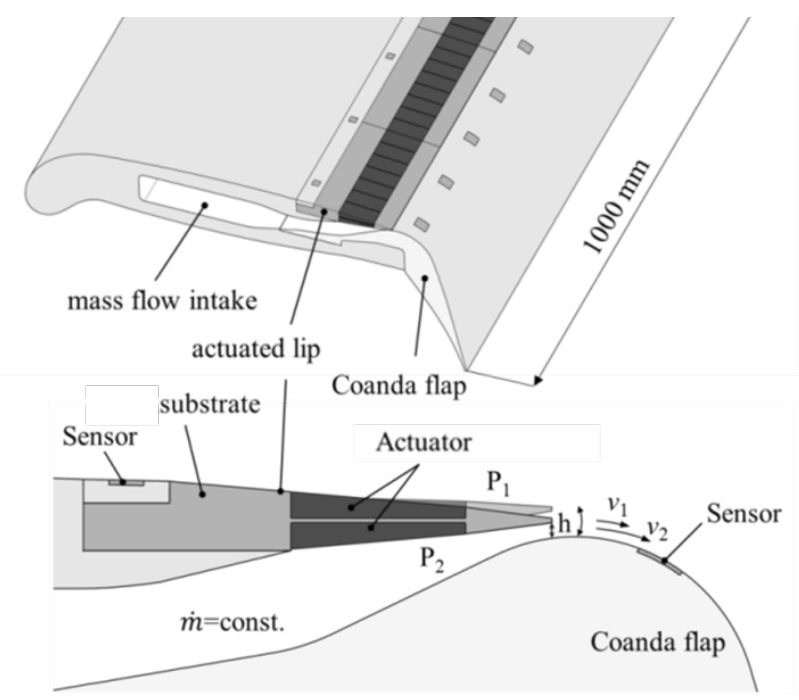

Figure 1. Concept of the blown Coanda flap with active flow control. Top: general view of the wing section; Bottom: detailed view of a generic bending transducer to control the blowing slot and functional principle of the active flow control system.

It has been proven that active flow control (AFC) with periodic actuation provides aerodynamic advantages (e.g., [2-4]). These advantages result from the power reduction compared to continuous operation of the flow control system. The effectiveness of periodic actuation is based on the exploitation of flow instabilities in contrast to a steady actuation that tries to change the flow topology by momentum injection. Circulation control in combination with high lift devices offers several advantages compared with conventional high lift configuration. The basic concept of circulation control includes the Coanda principle, in which energy is introduced into the flow by means of a thin jet that is ejected tangentially from a slot near the trailing edge. The main advantage of circulation control is increased lifting capacity, which enables shorter take-offs and landings. This technology was patented in 1960 by Davidson [5] and has been studied in various publications since then [6-8]. A circulation control wing (CCW) with steady jets has been shown to provide lift coefficients that are comparable or superior to conventional high lift systems, even with very small mass flows $[9,10]$. A special variant of the circulation control is the Coanda flap, with the objective to keep the flow attached over a highly deflected flap, by blowing a jet tangentially over the specially designed surface contour. This concept has already been examined and geometrically optimized in several previous studies [11-13]. To the best of the authors' knowledge, an actuator concept with the complexity presented in this study has not yet been investigated.

\section{Requirements and Actuation Principle}

As part of this work, a scaled wind tunnel model with a span of $1 \mathrm{~m}$ and a chord of $600 \mathrm{~mm}$ has to be equipped with the active lip. The very limited dimensions of the scaled wind tunnel model represent an enormous challenge for the development of the active system (Figure 2). Additionally, 
there are requirements that result from the aerodynamic function of the lip. The main requirements are an operating frequency of up to $\mathrm{f}=300 \mathrm{~Hz}$, an active displacement of $\mathrm{h}=0.4 \mathrm{~mm}$ at the tip of the lip, and the operability at a plenum pressure of 1 bar. Besides this, there is the necessity for a lightweight design to keep the resonance frequency of the system above $300 \mathrm{~Hz}$. To allow a span wise variable actuation (3D-actuation), the lip is subdivided into 33 individually controllable segments with a width of $29 \mathrm{~mm}$ each. This segmentation is a compromise between aerodynamic resolution and complexity of the mechanical system.

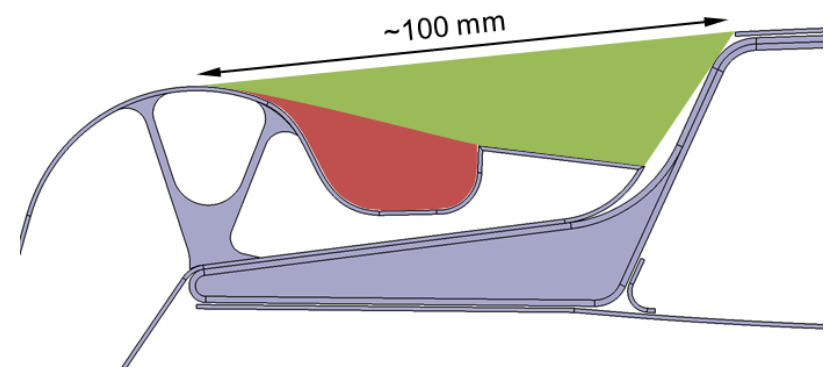

Figure 2. The picture shows a cross section through the rear part of the profile just before the Coanda flap. The green area indicates the available space for installing the active system. The plenum is indicated by the red area.

Another requirement arises from the practical operation of the system. Differences in the rigidity of the lip segments and assembly tolerances must be compensated by an adjustment mechanism of the lip segments so that the gap height can be set precisely to calibrate each lip segment.

Based on these requirements, it became clear that the task can only be solved with a solid-state actuator. Mechanical systems based on electromagnetic, pneumatic or hydraulic concepts are either too bulky, or their dynamics are too limited. The diagram in Figure 3 shows a comparison of different actuators by means of power output per unit volume and operation frequency [14]. Compared to other actuation concepts, piezoceramics in particular have very good properties in this regard. Taking these considerations into account, a concept based on piezoceramic actuators was selected. The major disadvantage of piezoceramic actuators is their low stroke. For piezo actuators using the larger longitudinal effect (or $\mathrm{d}_{33}$-effect), the free active strain is approx. $1000 \mu \mathrm{m} / \mathrm{m}$. In order to achieve the required deflection of $0.4 \mathrm{~mm}$, an amplification of the actuator stroke is therefore necessary. For this purpose, two different amplification concepts were examined for their principal applicability to this problem.

The first concept is based on a piezoceramic bender configuration, as depicted in Figure 4a. The principle is based on thin piezoceramic patch actuators that are bonded to a structural substrate. A contraction or expansion of the piezoceramic patch leads to a bending deformation of the assembly. A basic distinction is made between a monomorph-, bimorph- or trimorph configuration. In a monomorph configuration, a single piezoceramic layer is applied to the substrate. In the bimorph configuration, two piezoceramic layers, without a structural substrate, are arranged one above the other. In the trimorph configuration, there are two piezoceramic layers, which are usually arranged symmetrically with a substrate material. Each of these configurations has advantages and disadvantages in terms of maximum deflection and achievable forces and rigidity. In particular, rigidity plays a major role, since the deformations due to the aerodynamic loads should be as small as possible, in order to enable a precise adjustment of the blowing slot. With this in mind, trimorph configurations are most suitable for this task, because they achieve the best ratio of stiffness to active deflection. In order to increase the rigidity and blocking force, it is possible to arrange several layers of piezoceramic patch actuators on top of each other. However, this leads to a reduction in free deflection. To ease this problem, the number of piezoceramic layers can be successively reduced, starting from the clamping 
of the bending transducer. However, the manufacturing of such configurations is complex, costly and error-prone.

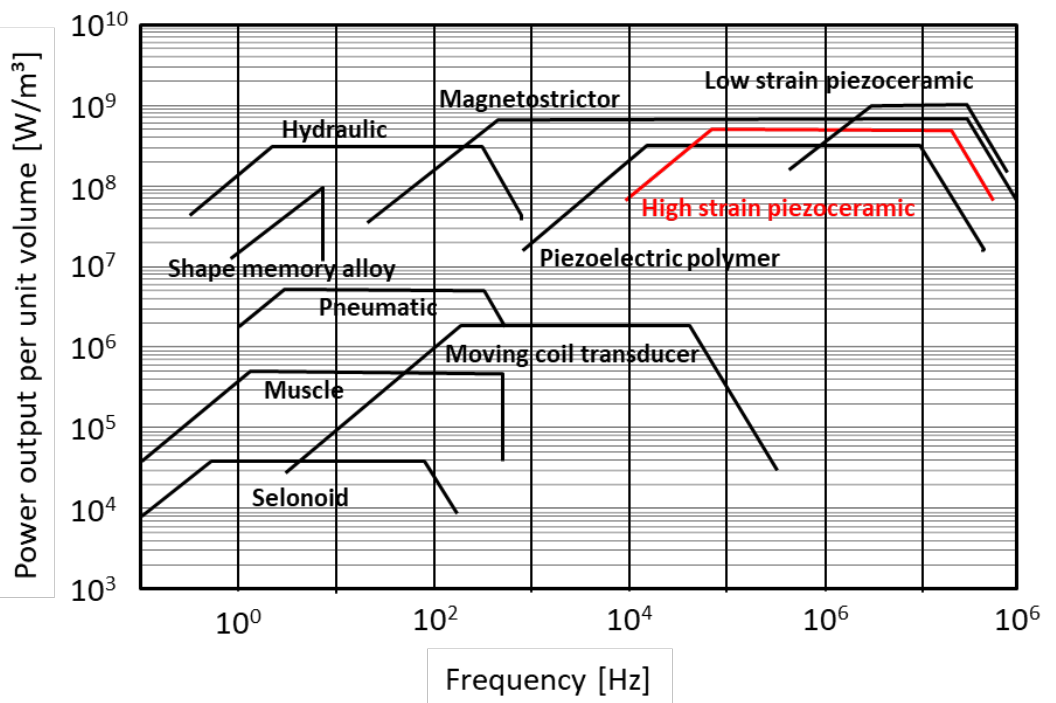

Figure 3. Comparison of different actuators by means of power output per unit volume and operation frequency (the data were taken from [14]).

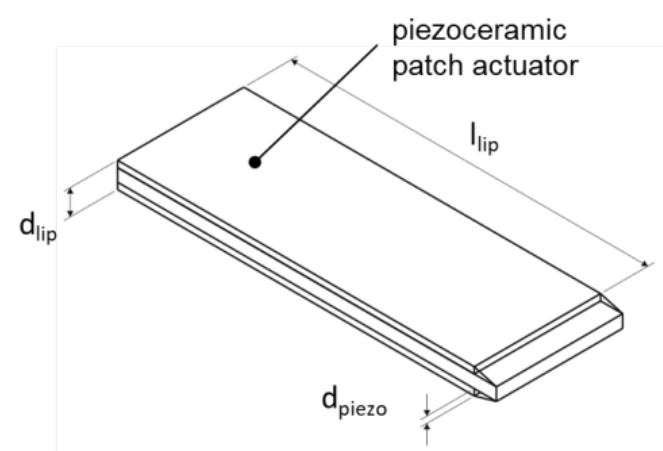

a)

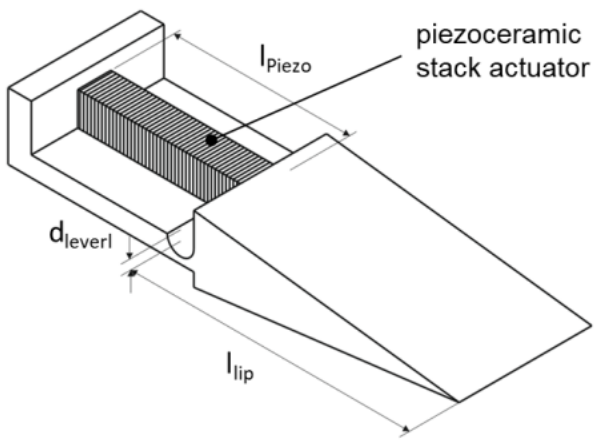

b)

Figure 4. Actuator concepts for the active lip of the blown slot. (a) Piezoceramic bender in a trimorph configuration; (b) Compliant leverage with a piezoelectric stack actuator.

For piezoceramic patch actuators, only the longitudinal ( $\mathrm{d}_{33}$-effect $)$ and the transversal $\left(\mathrm{d}_{31}\right.$-effect) effect are used for technically relevant applications [15]. The arrangement of the electrodes determines which effect will be used. The simplest configuration can be realized by using the $\mathrm{d}_{31}$ effect. In this case, the in-plane contraction of the piezoceramic material (i.e., Poisson's ratio effect) is used when a positive electrical field is applied in a direction normal to the thickness of the piezoceramic material (usually a thin piezoceramic plate). Thus, the piezoceramic plate is provided with very thin layers of conductive material (a few $\mu \mathrm{m}$ ), to build uniform surface electrodes. The electrical field is generated homogenously between these electrodes. The thickness of the piezoceramic plate defines the distance between the upper and lower electrode, and therefore the voltage that is needed to generate a certain electrical field. With a usual plate thickness of $0.2 \mathrm{~mm}$, a voltage of $200 \mathrm{~V}$ is necessary to generate an electrical field of $1 \mathrm{kV} / \mathrm{mm}$.

Up to three times higher deformations can be achieved with the $d_{33}$-effect. In this case, the electrical field and the effective deformation are in the same direction. Applying a positive field will result in an expansion of the piezoceramic device in the direction of the field and a contraction perpendicular to this direction. The challenge is the generation of an in-plane electrical field. A feasible technical solution is 
the use of interdigitated electrodes [16,17]. Usually, the electrodes are made of two comb-like electrodes with opposite polarity, which are applied on the surface of the piezoceramic material. The electrical field is generated between the fingers of the electrode and penetrates the piezoceramic material. Due to this design, the electrical fields are not very homogenous. This has a direct impact on the minimum electrode distance and hence on the operating voltage. If the distance between the electrode fingers is too small in comparison to the thickness of the piezoceramic material, the electrical field cannot sufficiently penetrate the piezoceramic material and the efficiency of the actuator is reduced. Additionally, the areas directly below the electrode fingers do not contribute to the actuation strain. If the electrode distance is reduced, the number of electrode fingers increases, as does the "dead" area below the electrodes. This can only partly be compensated by using very thin electrode fingers. Besides technical limitations in producing very thin electrode fingers, such a configuration will also cause very high electrical field gradients in the vicinity of the electrodes. These high gradients lead to high mechanical loads in the piezoceramic material, resulting in an impact on lifetime and durability. A suitable electrode distance for a piezoceramic device with a thickness of $0.2 \mathrm{~mm}$ is between 0.5 and $1 \mathrm{~mm}$. In this case, without considering the field inhomogeneity, a voltage of 500-1000 V is necessary to generate an electrical field of $1 \mathrm{kV} / \mathrm{mm}$. Despite the higher electrical voltage and the more complex structure, it is crucial for this task to select an actuation principle that generates maximum deflection, and it is therefore necessary to only consider $d_{33}$ patch actuators.

The second concept is based on a compliant leverage mechanism with a piezoceramic stack actuator, as depicted in Figure $4 \mathrm{~b}$. A piezoceramic stack actuator consists of a large number of piezoceramic plates, that are stacked on top of each other and generally glued together. The plates are provided with surface electrodes and expand in the thickness direction when an electric field is applied, in accordance with the $\mathrm{d}_{33}$-effect. The maximum stroke of the actuator is defined by the number of plates, while the operating voltage is determined by the thickness of the individual plates. A distinction is typically made between high- and low voltage stack actuators. Low-voltage actuators are typically built up from plates with a thickness of $0.2 \mathrm{~mm}$ and require an electrical voltage of up to $400 \mathrm{~V}$. The plates of high-voltage actuators are usually $0.5 \mathrm{~mm}$ thick and are operated with a voltage of $1000 \mathrm{~V}$. High-voltage actuators have the advantage over low-voltage actuators that they have a higher rigidity, since fewer adhesive layers are required to produce a stack of the same length, and therefore active deflection. In addition to glued stack actuators, so-called multilayer stack actuators are also available. Here, the electrodes are sintered directly into the ceramic body as thin layers and therefore have little effect on the stiffness of the actuator. This design allows very small electrode spacings, which enables operating voltages of less than $100 \mathrm{~V}$. Due to their special design, the maximum dimensions of such a multilayer stack are limited, as large parts cannot be sintered in one piece. However, it must be noted that the electrical power required for the operation of the actuators is approximately the same for all variants, since a smaller electrode distance is always accompanied by an increase in the capacity of the actuator.

The various actuator concepts were qualitatively assessed based on the requirements described above. The analysis showed that it is only possible with extremely complex piezoceramic bender configurations to meet the requirements regarding rigidity. The result of this assessment is summarized in Table 1. The evaluation shows that the variant with a compliant leverage mechanism is most advantageous and that the advantages outweigh the disadvantages.

Table 1. Evaluation of various design concepts for the active lip.

\begin{tabular}{lccc}
\hline \multicolumn{1}{c}{ Criterion } & Bender & Multilayer Bender & Compliant Leverage \\
\hline Deflection & + & 0 & 0 \\
Blocking force & - & 0 & + \\
Rigidity & - & 0 & + \\
Installation space & + & 0 & + \\
Robustness & 0 & - & 0 \\
Manufacturing effort & 0 & - & 0 \\
Cost & + & - & + \\
Adjustability & - & - & + \\
Reparability & - & & \\
\hline
\end{tabular}




\section{Detailed Design of the Actuation Mechanism}

For the detailed design of the active lip, it was first investigated which piezoceramic stack actuators are best suited for this application. Depending on the length of the lip $\left(l_{\text {lip }}\right)$ and the leverage $\left(\mathrm{d}_{\text {lever }}\right)$, Equation (1) describes, which actuator stroke $\left(\mathrm{s}_{\text {act }}\right)$ is required to achieve a deflection of $\mathrm{s}_{\text {tip }}$ at the tip of the lip. Assuming a deflection of $\mathrm{s}_{\text {tip }}=0.5 \mathrm{~mm}(0.4 \mathrm{~mm}$ is required) the result of this equation is depicted in Figure 5 for different leverages.

$$
\mathrm{s}_{\text {act }}=\mathrm{s}_{\text {lip }} \frac{\mathrm{d}_{\text {lever }}}{1_{\text {lip }}}
$$

The green area in Figure 5 indicates leverages above $2 \mathrm{~mm}$. The smaller the leverage, the greater the gear ratio, but the greater the mechanical load on the mechanism. Furthermore, the lever length cannot be chosen too short from a design point of view. Based on these considerations, the minimum lever length was set to $2 \mathrm{~mm}$. In addition, the stroke of various commercial piezo stack actuators is plotted in the diagram. The best performance is shown by a high-voltage actuator that generates a stroke of $60 \mu \mathrm{m}$, with a length of $54 \mathrm{~mm}$ (type P-010.40 [18]). With a lip length of less than $30 \mathrm{~mm}$, this actuator already achieves the required deflection at the tip of the lip.

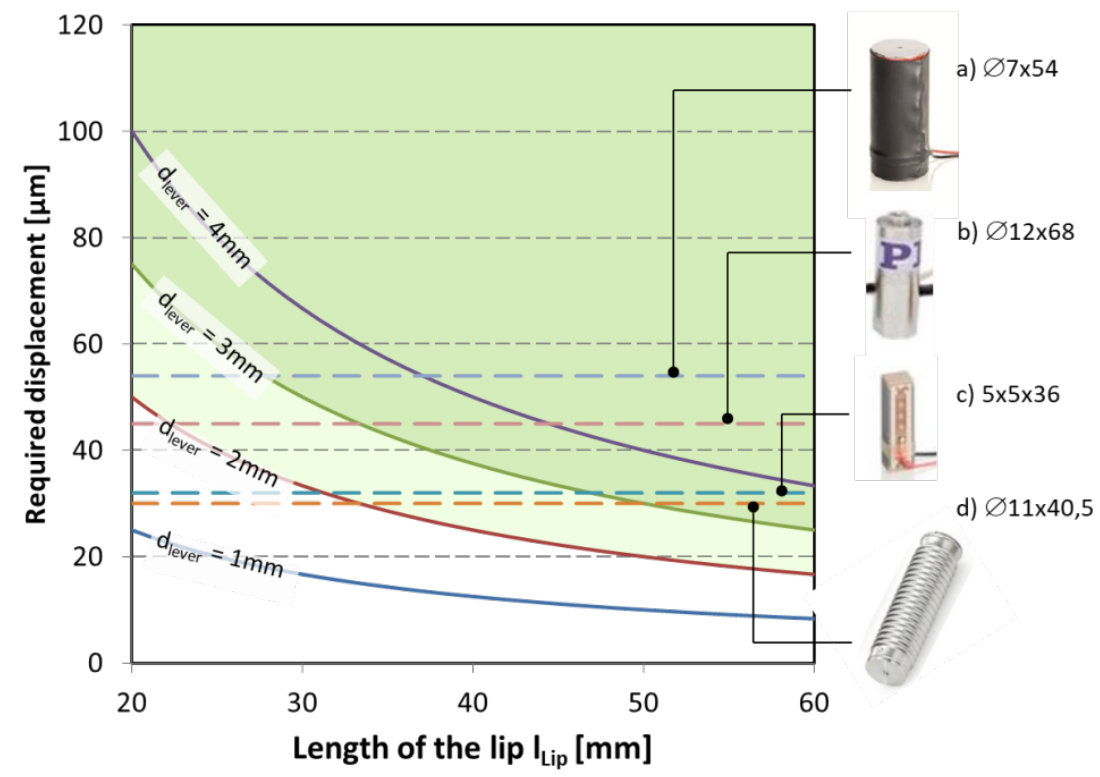

Figure 5. Required actuator stroke and lip length for various leverages $\left(\mathrm{d}_{\text {lever }}\right)$ to achieve a deflection of $0.5 \mathrm{~mm}$ at the lip tip, compared with the stroke of different commercial stack actuators. (a) High voltage stack actuator type P-010.40 [18]; (b) High voltage stack actuator with housing type P-841.3 [19]; (c) Multilayer stack actuator type P-885.95 [20]; (d) Multilayer stack actuator with housing type P-885.91 [21].

Based on these considerations, a more detailed analytical model based on a Bernoulli beam to describe the compliant hinge was created as shown in Figure 6. Neglecting the plenum pressure, the free deflection at the lip tip can be calculated using Equation (2), where E denotes the modulus of elasticity and $\mathrm{I}_{\mathrm{y}}$ the area moment of inertia of the hinge.

$$
\mathrm{s}_{\text {lip }}=\frac{\mathrm{d}_{\text {lever }} \mathrm{F}_{\text {act }} \mathrm{t}_{\text {hinge }}^{2}}{2 \mathrm{EI}_{\mathrm{y}}}+\frac{l_{\text {lip }} \mathrm{s}_{\text {act }}}{\mathrm{d}_{\text {lever }}}
$$

A parameter study was carried out to investigate the influence of different configurations. As mentioned before, the deflection of the lip strongly depends on the distance between the neutral 
fiber of the solid-state hinge and the axis of force application point $\left(\mathrm{d}_{\text {lever }}\right)$. The detailed design of the actuated lip was then developed in an iterative process. Finite element models were used for stress analysis and to determine the deformation behavior of the lip under aerodynamic loads. During this phase, several prototypes were built and tested with 3D printing technologies, to allow an evaluation of the concept at an early stage.

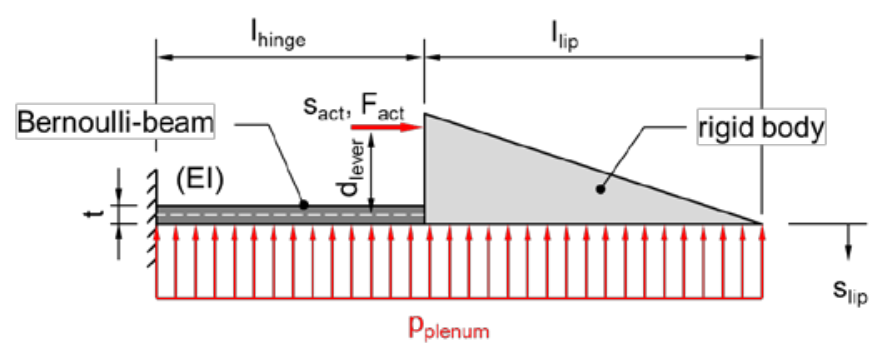

Figure 6. Simplified model of the actuated lip.

The final design of the lip segment is equipped with the high voltage piezoelectric stack actuator mentioned before, having a length of $56 \mathrm{~mm}$ and a diameter of $10 \mathrm{~mm}$ (type P-010.40 Physik Instrumente (PI) Ceramic). This actuator generates a free displacement of $60 \mu \mathrm{m}$ and has a blocking force of $2.2 \mathrm{kN}$. The lever mechanisms translate this stroke into a $0.6 \mathrm{~mm}$ movement of the lip tip in the unloaded case and $0.4 \mathrm{~mm}$ in the loaded case (1 bar plenum pressure). The flexure hinge is composed of a carbon fiber laminate with a thickness of $0.5 \mathrm{~mm}$. To reduce the weight of the lip, the main body is made of aluminum, whereas the lip tip is made of hardened steel to provide sufficient wear resistance and stiffness against aerodynamic loads. Because of the limited available space, and due to the requirement that no components should protrude from the aerodynamic contour, a punch is used to transfer the deflection of the actuator to the tip of the lip. This punch is guided into a Teflon sleeve in the aluminum body in order to minimize friction losses. The stack actuator itself is inserted in an aluminum sleeve, which is screwed into the aluminum body with a thread. The position of the lip tip can be adjusted by screwing the aluminum sleeve in and out. Once the correct position has been found, the sleeve can be fixed with a clamping screw. The final dimensions and design of the different components of the lip are shown in Figure 7.

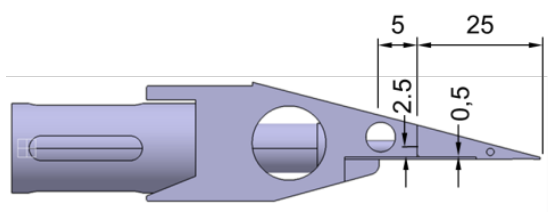

a)

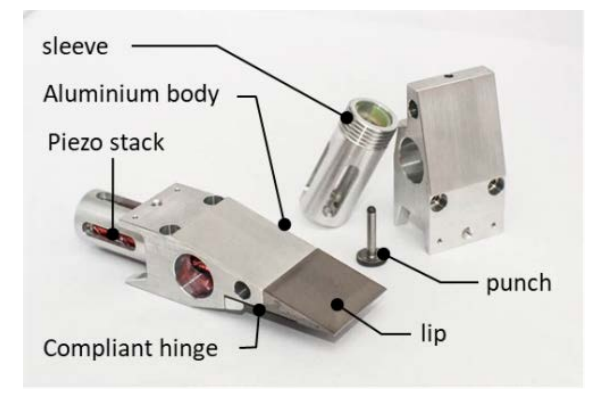

b)

Figure 7. Final dimensions and design of an actuated lip segment: (a) CAD model with essential dimensions; (b) Realized functional model.

The design process of the lip segment was accompanied by various finite element simulations, in order to examine critical components in more detail. Since the entire mechanical design of the lip was carried out in CATIA V5 (Dassault Systèmes, Vélizy-Villacoublay, France), the finite element program integrated in CATI V5 was used for this purpose. The actuation of the piezo stack is modelled using the thermomechanical analogon (the piezoelectric coefficient is represented by a matched coefficient 
of thermal expansion). Figure 8 illustrates an exemplary result of such a simulation. With the finite element model, it can be shown that the influence of the Teflon sleeve, in view of actuation losses, is sufficiently low. Later, lab experiments prove those results. To get an assessment of the von Mises stress, the pressure was increased up to one bar. The largest stress is expected at the contact point between the punch and the metal lip. Therefore, those two parts are made of hardened steel.

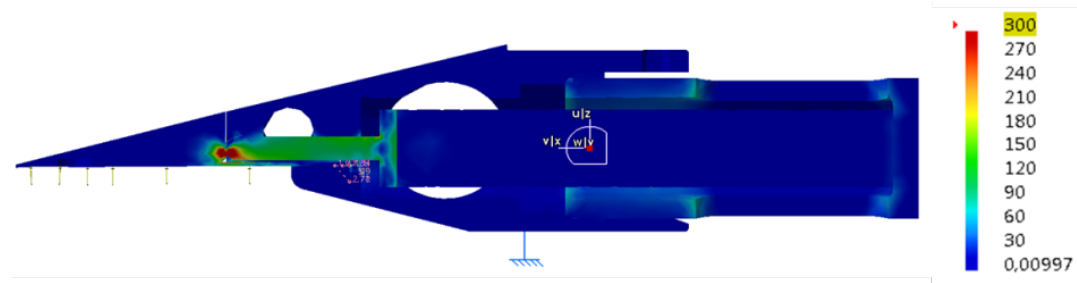

Figure 8. Exemplary result of a finite element calculation of the lip (von Mises stress); the highest loads are found at the contact point between the punch and the metal lip; no critical load cases were found.

Rapid prototyping was used at an early stage of the design process, to support the development process. With the help of 3D printing, it was possible to verify the kinematics, as well as the geometric properties. The design at the starting point was a single-piece box-shaped actuator, shown in Figure 9 on the top left.

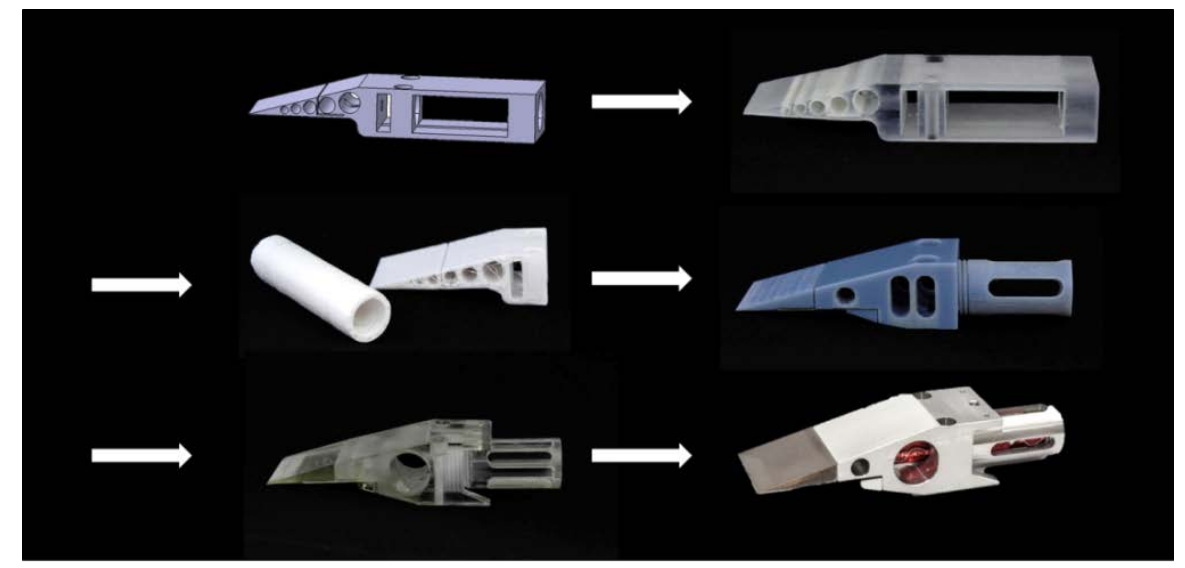

Figure 9. Design evolution from a box-shaped design to the final actuator.

\section{Results and Discussion}

\subsection{Mechanical Characterization of the Actuation Mechanism}

In order to test the lip under aerodynamic loads, a test rig with a pressurized plenum was built (Figure 10). The test rig allows the installation of three lip segments side by side. The displacement was measured using a laser triangulator (optoNCDT 1420-10, Micro-Epsilon, Ortenburg, Germany), with a measurement range of $10 \mathrm{~mm}$ having a resolution of less the $1 \mu \mathrm{m}$. The measured frequency depended displacement of the actuated lip is plotted in Figure 11 for different actuation voltages. The plenum was pressurized with one bar according to a pressure sensor mounted in the plenum. The required displacement of $0.4 \mathrm{~mm}$ at the lip tip was achieved over the relevant frequency range (marked in green) with a nominal actuation voltage of $1000 \mathrm{~V}$. To determine the resonance frequency, the actuation voltage was reduced to avoid too high resonance displacements. The diagram shows clearly that the resonance frequency is well above $300 \mathrm{~Hz}$. The test rig was also used to determine the long-time behavior of the lip segments. After $5 \times 10^{8}$ load cycles at full voltage and with a frequency of $300 \mathrm{~Hz}$, no reduction of the active performance was observed. In particular, no wear on the friction 
pair between the punch and lip could be observed. Based on these laboratory results, it was therefore possible to take the step to produce a complete set for equipping the wind tunnel model.

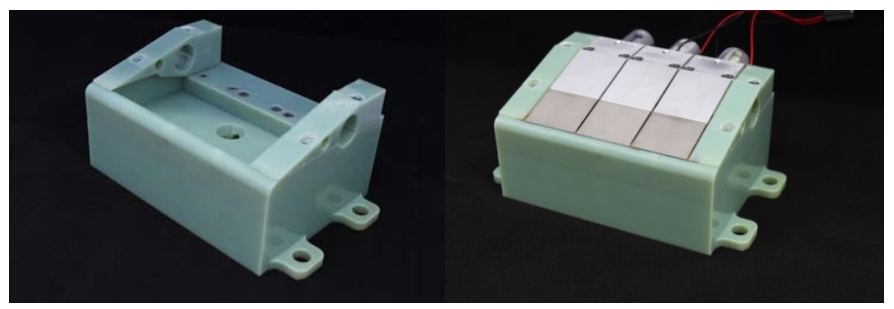

Figure 10. Left: test plenum without lip segments; right: test plenum with the final lip segments.

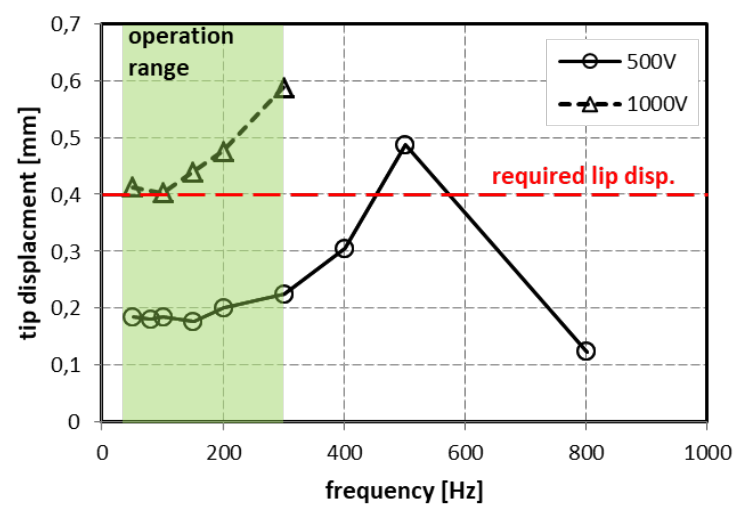

Figure 11. Lip displacement at different frequencies and actuation voltages at a plenum pressure of one bar.

\subsection{Integration into the Wind Tunnel Model}

Figure 12a (left) depicts the complete lip, with all 33 segments mounted onto a rail to facilitate the assembly and the integration into the wind tunnel model (Figure 12b). The gaps between the lip segments are sealed with an adhesive tape that is applied from below. The tape is flexible enough not to hinder the movement of the lips. Then, the height of the initial gap must be set to the required value. This is done by screwing the sleeve of the piezo stack actuator in or out, using a feeler gauge as reference. When the correct position has been found, the sleeve is fixed with a clamping screw. This process must be carried out with great care. Since the active lip and the attachment point to the wind tunnel model are flexible, the lip gap must be adjusted under aerodynamic pressure. The adjustment was therefore done outside the wind tunnel, but with a pressurized plenum.

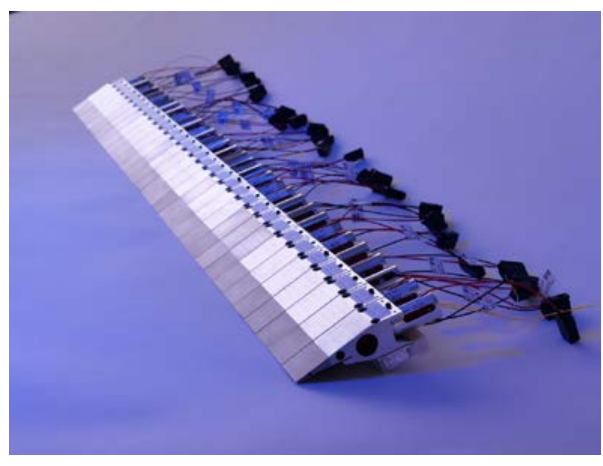

a)

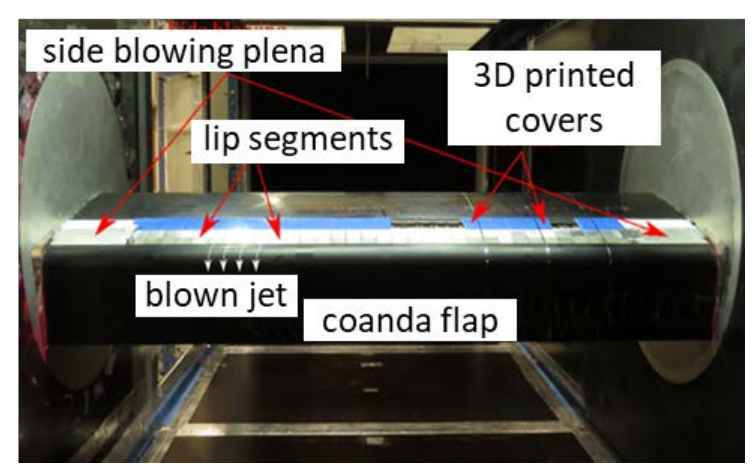

b)

Figure 12. (a) Thirty-three lip segments mounted on an assembly rail; (b) Wind tunnel model with installed lip segments. 
The tips of the lip segments are equipped with small neodymium magnets. In combination with integrated hall sensors below the skin of the Coanda flap, a direct measurement of the lip deflection during the wind tunnel test is, in principle, possible. Although the functionality of the sensors was demonstrated in the laboratory, signal cables were damaged during the installation of the sensors in the wind tunnel model so that the sensor system could ultimately not be used. Therefore, all measurements to characterize the performance of the active lip were carried out outside the wind tunnel with a pressurized plenum.

Optical deformation measurements of the lip with a pressurized plenum were carried out to examine the flexibility of the system more precisely. A digital image correlation (DIC) system (Aramis, GOM Messtechnik, Braunschweig, Germany) was used for this purpose. Figure 13 (top) shows a schematic view of a lip segment. Section 1 covers the rigid aluminum body that is mounted to the structure of the wind tunnel model, with two screws. Section 2 represents the lip tip made of hardened steel that is connected to the aluminum body with the compliant carbon reinforced plastics (CFRP) hinge. The diagram in Figure 13 shows the evaluation of the DIC measurement for a cross section in the middle of different lip segments. Discontinuities in the plotted curves result from errors in the detection of the deformation by the DIC system and do not reflect a real effect. The measured displacements result from the comparison of the pressurized and non-pressurized plenum. When comparing the different displacement curves with each other, slight differences between the lip segments can be seen. This is due to the different stiffnesses of the lip segments and the entire structure, leading to a different deformation of each lip. The maximum variation range at the lip tip in this evaluation is approx. $0.07 \mathrm{~mm}$. The fact that the curves are linear in sections shows that the individual components do not bend, but that these are rather rigid body movements around different pivot points (attachment point to the model and compliant hinge). The displacement curve for Section 1 is significantly flatter than the curve for Section 2, indicating that most of the deformation results from the softness of the actuator and the sleeve that holds the actuator. The part resulting from the softness of the clamping (Section 1) is marked with a " $b$ " in the diagram, while the part resulting from the softness of the actuator and sleeve (Section 2) is marked with an "a". In this case the deformation resulting from Section 2 is three times larger than the deformation resulting from Section 1. In total the lip tip is bent open by $0.4 \mathrm{~mm}$, due to the plenum pressure. This is in the order of magnitude of the active deflection of the lip and underlines the importance of adjusting the lip under pressure, also to compensate for the varying rigidity of each segment.
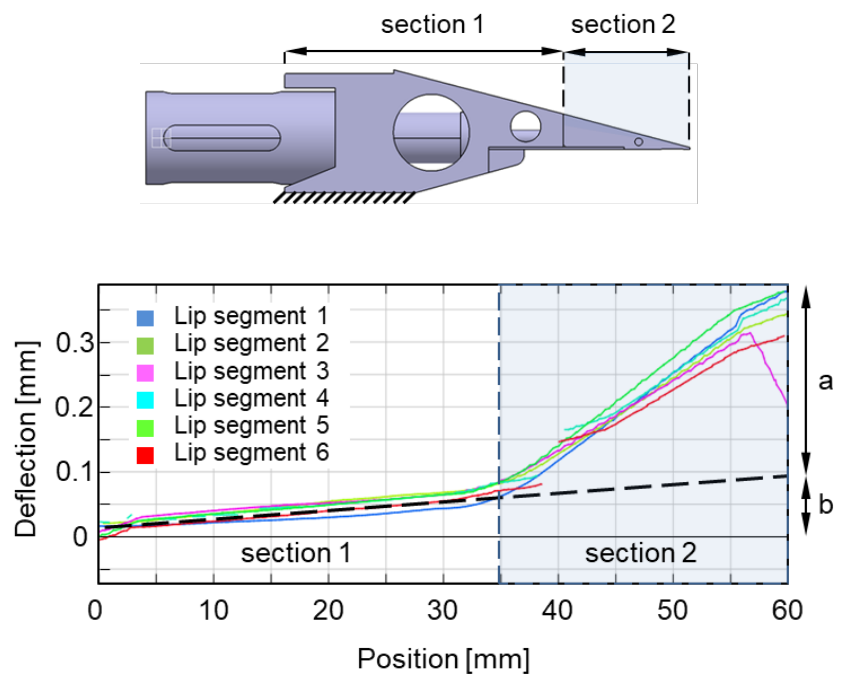

Figure 13. (Top) Schematic view of a lip segment; (Bottom) Displacement along the lip segment measured with a digital image correlation (DIC)-system at a plenum pressure of 0.6 bar. 
The measurements also show that the deformation of the different lip segments do not differ significantly. This finding is particularly important because it shows that the setting of a homogeneous gap is possible. Figure 14 shows the measurement of a lip segment at various pressures in the plenum. The result confirms that the basic deformation behavior of the lip is the same at different plenum pressures, and in good approximation a linear increase in the deformation at the tip of the lip can be assumed, with increasing pressure.

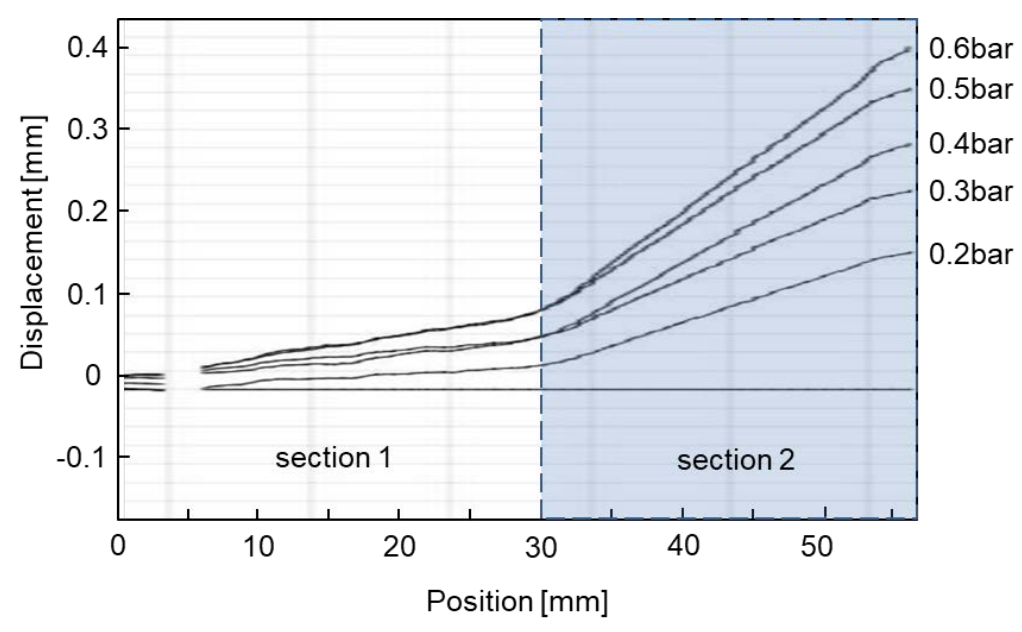

Figure 14. DIC measurement of the deformation of a lip segment at various plenum pressures (0.2-0.6 bar).

\section{Conclusions}

As part of this work, an actuator concept for active flow control of a blown Coanda flap was developed. To meet the challenging requirements with regard to installation space, dynamics and rigidity, the concept is based on a piezoceramic stack actuator in combination with a compliant lever mechanism. Prototypes were developed and tested in an iterative design process. It was shown that the actuator can adjust the height of the blowing slot under pressure over the entire frequency range. Long-term tests demonstrated that the system shows no signs of wear or performance loss, even after $5 \times 10^{8}$ load cycles. A wind tunnel model with a span of $1 \mathrm{~m}$ and a chord of $0.6 \mathrm{~m}$ was equipped with 33 individual actuators, to allow 3D-actuation of the blowing slot. The deformation behavior of the active lip was extensively investigated with high resolution using the Digital Image Correlation technique (DIC). The flexibility of the entire mechanical system plays a major role in setting the slot to the required tolerances and must be taken into account when installing the system. It is therefore necessary to adjust the system with a pressurized plenum, since the deformations that occur under pressure are in the order of magnitude of the active deflection of the lip. This process is very complex and must be carried out with great care.

So far, preliminary wind tunnel tests showed an increase in lift of up to $\Delta C_{a}=0.57$. These aerodynamic gains are achieved at amplitudes that do not require the lip segments to completely close or open the blowing slot, which shows the advantage of the current lip design that enables activation with independently controlled stationary and unsteady components. Details about the wind tunnel test results are reported in [22].

Although wind tunnel measurements can be carried out with the existing system, some potential for improvement has been identified. In particular, the correct manual setting of the blowing slot is very time consuming and error prone. The possibility of automatically setting the slot height would considerably simplify test preparation. This can be done by a rough manual adjustment of the lip segments and a subsequent fine adjustment by the actuator itself. However, this requires an accurate measurement of the slot height for each segment. In principle, it could be shown that this is possible with integrated Hall effect sensors. It is therefore recommended to equip each lip segment with such a 
sensor. This would also enable a measurement of the actual slot height during the wind tunnel test and would provide additional valuable information for the active flow control algorithms.

Furthermore, the precision when installing the lip segments can be improved by combining several aluminum bodies (see Figure $7 \mathrm{~b}$ ) into larger modules. In principle, such a module could cover the entire span of the model. However, the production of such a module would be very complex, so that it makes sense to divide it into three modules, each of which can accommodate 11 lip segments. As a result, only three larger components would have to be installed and aligned in the wind tunnel model.

With the implementation of these enhancements, significantly improved results for future wind tunnel tests are expected.

Author Contributions: P.W. organized the contents, developed the principle design of the active lip segments and defined the test procedures. J.P. carried out the detailed lip design, organized the manufacturing and carried out the experimental work. M.S. supervised the work and provided a number of key suggestions. All authors have read and agreed to the published version of the manuscript.

Funding: Financial support has been provided by the German Research Foundation (Deutsche Forschungsgemeinschaft-DFG) in the framework of the collaborative research center SFB 880-Fundamentals of High Lift for Future Commercial Aircraft.

Acknowledgments: The authors would like to thank Rolf Radespiel, Yosef El-Sayed, Stephan Sattler and Richard Semaan from the Institute of Fluid Mechanics of the Technical University of Braunschweig for the many constructive discussions, the help in compiling the state of the art, and the implementation of the wind tunnel tests.

Conflicts of Interest: The authors declare no conflict of interest. The founding sponsors had no role in the design of the study; in the collection, analyses, or interpretation of data; in the writing of the manuscript, and in the decision to publish the results.

\section{References}

1. Radespiel, R.; Heinze, W.; Bertsch, L. High-Lift Research for Future Transport Aircraft 05.-07.; 66 Deutscher Luft-und Raumfahrtkongress (DLRK): München, Deutschland, 2017.

2. Greenblatt, D.; Wygnanski, I. The control of flow separation by periodic excitation. Prog. Aerosp. Sci. 2000, 36, 487-545. [CrossRef]

3. Barros, D.; Bor'ee, J.; Noack, B.R.; Spohn, A.; Ruiz, T. Bluff body drag manipulation using pulsed jets and Coanda effect. J. Fluid Mech. 2016, 805, 422-459. [CrossRef]

4. Chabert, T.; Dandois, J.; Garnier, A. Experimental closed-loop control of separated-flow over a plain flap using extremum seeking. Exp. Fluids 2016, 57, 37. [CrossRef]

5. Davidson, I.M. Aerofoil boundary layer control system. Br. Pat. 1960, 913, 754.

6. Lachmann, G.V. Boundary Layer and Flow Control: Its Principles and Application; Pergamon Press: New York, NY, USA, 1961.

7. Wood, N.J.; Nielsen, J.N. Circulation Control_Past, Present and Future; AIAA Paper-85-0204; Stanford University: Stanford, CA, USA, 1985.

8. Englar, R. Circulation Control Pneumatic Aerodynamics: Blown Force and Moment Augmentation and Modifications. In Past, Present, and Future; AIAA Paper-2000-2541; Stanford University: Stanford, CA, USA, 2000.

9. Sexstone, M.G.; Huebner, L.D.; Lamar, J.E.; McKinley, R.E.; Torres, A.O.; Burley, C.L.; Scott, R.C.; Small, W.J. Synergistic Airframe-Propulsion Interactions and Integrations. In Tech. Rep. NASA/TM-1998-207644; NASA Langley Research Center: Hampton, VA, USA, 1998.

10. Smith, A.M.O. High-lift aerodynamics. J. Aircr. 1975, 12, 501-530. [CrossRef]

11. Jensch, C.; Pfingsten, K.C.; Radespiel, R.; Schuermann, M.; Haupt, M.; Bauss, S. Design Aspects of a Gapless High-Lift System with Active Blowing; 58. Deutscher Luft-und Raumfahrtkongress: Aachen, Germany, 2009.

12. Radespiel, R.; Pfingsten, K.-C.; Jensch, C. Flow analysis of augmented highlift systems. In Hermann Schlichting-100 Years; Radespiel, R., Rossow, C.C., Brinkmann, B.W., Eds.; Springer: Berlin, Germany, 2009; pp. 168-189.

13. Radespiel, R.; Burnazzi, M.; Casper, M.; Scholz, P. Active flow control for high lift with steady blowing. Aeronaut. J. 2016, 120, 171-200. [CrossRef] 
14. Huber, J.E.; Fleck, N.A.; Ashby, M.F. The Selection of mechanical actuators based on performance indices. Proc. R. Soc. Land 1997, 435, 2185-2205. [CrossRef]

15. Wierach, P.; Opitz, S.; Kalow, S. Experimental investigation of an active twist model rotor blade with a low voltage actuation system. Aeronaut. J. 2015, 119, 1499-1512. [CrossRef]

16. Bent, A.A.; Hagood, N.W.; Rodgers, J.P. Anisotropic Actuation with Piezoelectric Fiber Composites. J. Intell. Mater. Syst. Struct. 1995, 6, 338-349. [CrossRef]

17. Wilkie, W.; High, J.; Mirick, P.; Fos, R.; Little, B.; Bryant, R.; Hellbaum, R.; Jalink, A. Low Cost Piezocomposite Actuator for Structural Control Applications. In Proceedings of the SPIE's 7th International Symposium on Structures and Materials, Newport Beach, California, CA, USA, 5-9 March 2000.

18. PI-Piezo Technology, P-007-P-056 PICA Stack Piezo Actuators. Available online: https: //www.piceramic.de/de/produkte/piezokeramische-aktoren/gestapelte-aktoren/p-007-p-056-pica-stackpiezoaktoren-102600/\#specification (accessed on 16 December 2019).

19. PI-Piezo Technology, P-841 Preloaded Piezo Actuators. Available online: https://www.physikinstrumente. de/de/produkte/piezoelektrische-wandler-transducer-piezoaktoren/p-841-vorgespannte-piezoaktoren412418452/\#specification (accessed on 16 December 2019).

20. PI-Piezo Technology, P-882-P-888 PICMA®Stack Multilayer Piezo Actuators. Available online: https://www.piceramic.de/de/produkte/piezokeramische-aktoren/linearaktoren/p-882-p-888-picma-stackmultilayer-piezoaktoren-100810/\#specification (accessed on 16 December 2019).

21. PI-Piezo Technology, P-88x.x5 Encapsulated PICMA®Stack Piezo Actuators. Available online: https://www.piceramic.de/de/produkte/piezokeramische-aktoren/linearaktoren/p-88xx5-gekapseltepicma-stack-piezoaktoren-100805/\#specification (accessed on 16 December 2019).

22. El-Sayed, M.Y.; Oswald, P.; Sattler, S.; Pradeep, K.; Radespiel, R.; Behr, C.; Sinapius, M.; Petersen, J.; Wierach, P.; Quade, M.; et al. Open- and closed-loop control investigations of unsteady Coanda actuation on a high-lift configuration, Paper 3684. In Proceedings of the 2018 flow control conference, Atlanta, GA, USA, 25-29 June 2018.

(C) 2020 by the authors. Licensee MDPI, Basel, Switzerland. This article is an open access article distributed under the terms and conditions of the Creative Commons Attribution (CC BY) license (http://creativecommons.org/licenses/by/4.0/). 